\title{
Lessons Learned from Three Different Acellular Dermal Matrices in Direct-to-Implant Breast Reconstruction
}

\author{
Claas Spengler ${ }^{1 *}$, Roland Mett ${ }^{1}$, Frank Masberg ${ }^{1}$, Peter M. Vogt ${ }^{2}$, Tobias R. Mett ${ }^{2}$ \\ ${ }^{1}$ Department of Plastic, Reconstructive Aesthetic Surgery, HELIOS Klinik Schwerin, Schwerin, Germany \\ ${ }^{2}$ Department of Plastic, Aesthetic, Hand and Reconstructive Surgery, Hannover Medical School, Hannover, Germany \\ Email: *claasspengler@googlemail.com
}

How to cite this paper: Spengler, C., Mett, R., Masberg, F., Vogt, P.M. and Mett, T.R. (2021) Lessons Learned from Three Different Acellular Dermal Matrices in Directto-Implant Breast Reconstruction. Modern Plastic Surgery, 11, 22-35.

https://doi.org/10.4236/mps.2021.111004

Received: November 25, 2020

Accepted: January 10, 2021

Published: January 13, 2021

Copyright $\odot 2021$ by author(s) and Scientific Research Publishing Inc. This work is licensed under the Creative Commons Attribution International License (CC BY 4.0).

http://creativecommons.org/licenses/by/4.0/

\begin{abstract}
The aim of the study was to show significant differences regarding postoperative complications and outcomes using three different Acellular Dermal Matrices (ADM), namely Epiflex ${ }^{\circledast}$, Strattice ${ }^{\circledast}$ and Braxon ${ }^{\circledast}$, in immediate implant-based subpectoral breast reconstruction cases. Background: The use of Acellular Dermal Matrices for implant-based breast reconstruction cases continues to evolve. There is a wide variety of products which differ significantly in their biological features. It remains unclear if and how these differences manifest in clinical practice. Methods: 82 cases of primary breast reconstruction in the Department of Plastic and Aesthetic Surgery of HELIOS Clinics Schwerin, Germany between 2010 and 2018 were analyzed. 25 patients received Strattice ${ }^{\circledast}$ acellular dermal matrix (SADM), 22 cases Epiflex ${ }^{\circledast}$ acellular dermal matrix (EADM) and the remaining 35 cases Braxon ${ }^{\varpi}$ acellular dermal matrix (BADM). The mean follow-up was 1.8 years. Cases were analyzed regarding minor or major complications and rate of capsular contracture grade III or IV (Baker Classification). Results: The overall complication rate was $34.1 \%$ for all groups $(\mathrm{SADM}=40 \%, \mathrm{EADM}=50 \%, \mathrm{BADM}=20 \%$, p-value $=$ 0.051). Of all cases, 6 patients underwent implant exchange or secondary autologous reconstruction due to capsular contracture $(7.3 \%)$. The mean time between revision due to capsular contracture and reconstruction was $35.8 \pm$ 14.4 months. $50 \%$ of patients, who developed capsular contracture, received postoperative radiation. Mean hospitalization time was $8.2 \pm 3$ days (SADM = $8 \pm 3.2$ days, $\mathrm{EADM}=10 \pm 2.8$ days, $\mathrm{BADM}=6 \pm 1.3$ days). There were no significant differences between all three groups for demographics, overall complication rate or capsular contracture. However, patients receiving Braxon $^{\varpi}$ matrix showed significantly fewer minor complications ( $\mathrm{p}$-value $=0.01$ ). Moreover, patients receiving Braxon ${ }^{\circledast}$ ADM showed a significantly lower time
\end{abstract}


of hospitalization $(\mathrm{p}<0.001)$. Conclusion: No significant differences regarding the overall complication rate were found between the three groups. Different biological features of ADM showed a weak influence on overall results. However, patients receiving Braxon ${ }^{\circledR}$ ADM showed significantly lower minor complication rates and hospitalization time. In addition, these matrices showed a trend towards lower capsular contracture rates. The low rate of capsular contracture hints at possible advantages of ADM-use in direct-toimplant cases.

\section{Keywords}

Breast Reconstruction, Acellular Dermal Matrix, ADM, Direct-to-Implant, DTI, Immediate Breast Reconstruction, IBR, Breast Cancer, Skin Sparing Mastectomy, EPIFLEX, Strattice, BRAXON

\section{Introduction}

There is now widespread application of Acellular Dermal Matrices (ADM) for direct-to-implant (DTI) breast reconstruction. The reasons for this are mainly: 1) artificial elongation of the pectoralis muscle, which limits muscle dissection and surgical trauma and allows for increased initial fill volumes and faster expansion in expander-based cases [1];2) provision of an additional protection layer by enhancement of the soft tissue [2]; 3) better control of the inframammary fold and implant migration and the ability to shape the implant pocket, resulting in superior aesthetic outcomes [3] [4]; 4) possibly lower rates of capsular contracture, especially in the case of post-mastectomy radiation therapy (PMRT) [5].

ADMs may be derived from human, porcine or bovine tissue, resulting in different biological features (see Table 1). For example, the 1,3-alpha-Gal epitope is a known major xeno-antigen [6] present in porcine matrices. Although drastically reduced by enzymatic cleavage during the manufacturing process, it is not completely eliminated [7]. In line with this, a study by Roessner et al. still found residual DNA content on human-derived Epiflex ${ }^{\circledast}$ ADM [8]. Based on in vitro and in vivo findings, the host response towards different products may vary [9]. It is yet unknown if and how these experimental findings and different biological properties manifest in clinical practice.

Various studies examine and compare possible complication rates and postoperative results of different ADMs in breast reconstruction [9] [10] [11] [12]. However, these studies vary in terms of patient selection and surgical technique. For example, Paprottka et al. included primary or secondary aesthetic breast augmentation cases [13]. Salzberg et al. did ADM-assisted reconstruction in prophylactic cases in as much as $68 \%$ but did not find significant differences between oncologic and prophylactic cases [13]. To our knowledge, there is no study, which compares Braxon ${ }^{\oplus} \mathrm{ADM}$ with other ADM. This study examines the 
Table 1. Biological features and clinical applications of different ADM products.

\begin{tabular}{|c|c|c|}
\hline $\begin{array}{l}\text { Product name } \\
\text { Manufacturer }\end{array}$ & Product specifications and properties & Indications \\
\hline $\begin{array}{l}\text { Strattice } \\
\text { Life Cell Corp, } \\
\text { Brachburg, US }\end{array}$ & $\begin{array}{l}\text { Introduced 2008, licensed in Europe and US, porcine-derived, non-crosslinked, undergoes a } \\
\text { minimally manipulative manufacturing process with the aim to eliminate the alpha-Gal } \\
\text { epitope, thickness } 1-2 \mathrm{~mm} \text { provides chemotaxis and suppresses apoptotic induction [37] } \\
\text { loses tensile strength significantly in a mouse model between } 30 \text { days and } 3 \text { months [38] [39] } \\
\text { Seems to elicit an intense early immune response in mouse models [40] [41] with later shift } \\
\text { to beneficial M2:M1 ratio around day } 35 \text { [41] } \\
\text { Observed collagen deposition at later time points in mouse models [38] [39] [40] }\end{array}$ & $\begin{array}{l}\text { Breast Reconstruction } \\
\text { Abdominal Wall Repair }\end{array}$ \\
\hline $\begin{array}{l}\text { Epiflex } \\
\text { DIZG mbH, } \\
\text { Berlin, } \\
\text { Germany }\end{array}$ & $\begin{array}{l}\text { Human-skin derived, non crosslinked, thickness }>0.3 \text { and }>0.8 \mathrm{~mm}[42] \\
\text { preservation of significant ECM components such as collagen type I, type III, type IV, } \\
\text { fibronectin, laminin, vitronectin and hyaluronic acid seem to be preserved after } \\
\text { decellularization, small amounts of donor DNA remain }\end{array}$ & $\begin{array}{l}\text { Breast Reconstruction } \\
\text { Hypertrophic Scar Treatment } \\
\text { Dermis Replacement } \\
\text { Soft Tissue Replacement }\end{array}$ \\
\hline $\begin{array}{l}\text { Braxon }{ }^{\oplus} \\
\text { DECO med s.r.l., } \\
\text { Venice, Italy }\end{array}$ & $\begin{array}{l}\text { pre-shaped, non-crosslinked, } 0.6 \mathrm{~mm} \text { thick, porcine-derived matrix, shows mild fibroblastic } \\
\text { reaction and ingrowth of blood vessels after } 1 \mathrm{yr} \text { in humans [43], no chemical preservatives } \\
\text { used during manufacturing process }\end{array}$ & Breast Reconstruction \\
\hline
\end{tabular}

outcome of Epiflex ${ }^{\oplus}$, Strattice and Braxon ${ }^{\oplus}$ ADM application in immediate implant-based subpectoral breast reconstruction cases regarding overall minor and major complication rates and the development of capsular contracture.

\section{Methods}

A retrospective analysis of immediate subpectoral implant-based breast reconstruction cases between 2010 and 2018 in the department of Plastic and Aesthetic Surgery of Helios Clinics Schwerin, Germany was performed using our Hospital Information Software. We scanned for defined OPS procedures and ICD codes. We included all patients who were diagnosed with ductal carcinoma in situ (DCIS), invasive breast cancer and in whom skin-sparing or nipple-sparing mastectomy has been indicated as consented by the interdisciplinary tumor conference of the institution. Furthermore, all patients in whom prophylactic mastectomy has been indicated were included. We included all patients regardless of smoking status, BMI or comorbidities. Patients who underwent prepectoral or delayed reconstruction were excluded from the study. Patients who had partial or full autologous reconstruction (e.g. thoracoepigastric flap or latissimus dorsi flap) before were excluded. In addition, patients who received an ADM during primary or secondary aesthetic breast augmentation were excluded from the analysis. Patients were clustered into the Strattice ${ }^{\oplus}$ (SADM), Epiflex ${ }^{\oplus}$ (EADM) or Braxon ${ }^{\circledast}$ (BADM) group according to the ADM. For detailed description of these matrices see Table 1 .

The study was approved by the institutional review board of the University of Rostock, Germany (Registration-Number 2020-0037). Informed consent for the use of data and photographs for scientific purposes was given by each patient. The study is in full accordance with the Helsinki Declaration in its revised 2013 version.

The surgical technique was similar in all cases: After nipple or skin sparing mastectomy via a vertical incision, a limited subpectoral pocket was raised. Im- 
plant handling and insertion was done according to the principles given by Deva et al. 2013 [14]. In cases where Strattice ${ }^{\varpi}$ or Epiflex ${ }^{\circledast}$ have been used, a suitable piece of matrix was designed and sutured to the retracted pectoralis muscle as an inferolateral hammock for lower pole coverage as described earlier [15]. In cases where $\mathrm{Braxon}^{\circledR}$ matrix has been used, the whole implant was wrapped in matrix and completely covered by it. The inframammary fold was enforced by suturing the hammock down to the chest wall. The excess material of the matrix envelope was sutured down to the chest wall. In all cases, we have used one drain to the subpectoral pocket and one subcutaneous drain. A light pressure dressing was applied. Patients were put to bedrest for 24 hours. Drains were removed as soon as secretion had decreased under $30 \mathrm{ml}$ per day. All cases have been operated by a single author (R.M.) Exemplary pictures of preoperative markings and intraoperative technique are shown in Figure 1.

We analyzed patient charts and data with attention to age, mastectomy weight, implant size, operation time, days of hospitalization and complications. The retrospective endpoints of interest were minor complications such as hematoma, seroma or small-size skin necrosis not requiring revisional surgery, and major complications, defined as implant loss due to skin necrosis, seroma, hematoma or infection. Secondary endpoint was capsular contracture (Baker Classification III or IV) requiring late revisional surgery.

Group homogeneity was tested with either Pearson's Chi Square Test or Kruskal-Wallis Test, as appropriate. We tested statistical significance regarding the defined endpoints using Pearson's Chi Square Test. The significance level was given to a two-sided p-value of smaller than 0.05 . Statistical analysis was performed using the latest version of SPSS (IBM Corp., Armonk, New York, USA)
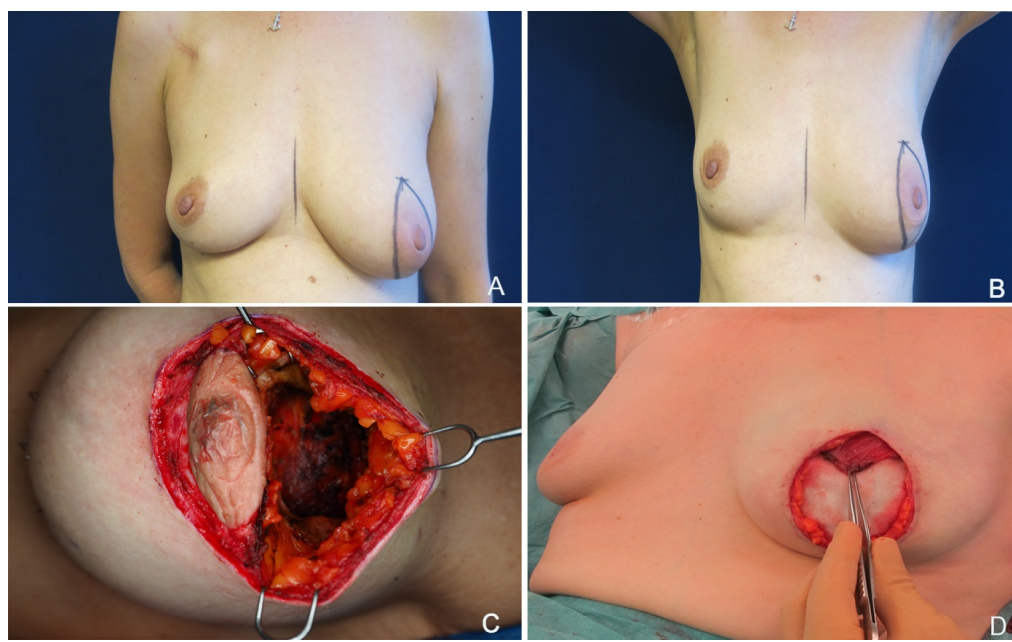

Figure 1. (A) Preoperative markings are shown for a 42-year-old woman with invasive ductal breast cancer of the left breast. (B) The vertical ellipse caudally extends to $2 \mathrm{~cm}$ above the inframammary fold. (C) Intraoperative view showing the gland which has been released from the pectoralis major muscle. A minimum of subcutaneous fat is preserved to maximize flap survival. (D) The implant has been wrapped completely in Braxon ${ }^{\circledR}$ matrix. The upper pole is secured beneath the raised pectoralis flap. 


\section{Results}

The analysis yielded 112 cases, of which 30 cases where excluded for not matching the preset requirements. In total, 82 cases remained, of which 25 cases received Strattice $^{\circledast}, 22$ cases Epiflex ${ }^{\circledast}$ and the remaining 35 cases Braxon ${ }^{\circledast}$. Mean follow-up was $1.8 \pm 1.1$ yrs.

The mean age of all patients was $50.3 \pm 11.62 \mathrm{yrs}$. The leading cause of mastectomy was invasive breast cancer (50\%), followed by DCIS (27\%) and prophylactic mastectomies (23\%). $27 \%$ of all patients underwent prior breast conservation therapy. Mean mastectomy weight was $353 \pm 177 \mathrm{~g}$ and mean implant size has been $373 \pm 111 \mathrm{cc}$. The mean operation duration was $157 \pm 50 \mathrm{~min} .15$ patients have received postmastectomy radiation therapy (PMRT). There were no significant differences between all groups except Follow-Up which was significantly shorter in the BADM group (see Table 2 ).

The overall complication rate was $34.1 \%$ for all groups $(\mathrm{SADM}=40 \%$, EADM $=50 \%, \mathrm{BADM}=20 \%)$. Although the absolute complication rate of the BADM group is lower than SADM or EADM, there was no significant difference ( $\mathrm{p}$-value $=0.051)$.

Minor complications occurred in 7 cases (8.5\%). There were significantly less minor complications in the BADM group vs. EADM (p-value $=0.003$ ). There were no significant differences between SADM vs. EADM or SADM vs. BADM ( $\mathrm{p}$-value $=0.158$ and 0.089 , respectively). In total, we have encountered 21 major complications leading to implant loss $(25.6 \%)$. There were no significant differences between the three groups regarding major complications (see Table 3 ). The main cause for implant loss was skin necrosis (52.4\%), followed by infection (23.8\%) and seroma (19\%).

Table 2. Summary of demographic and clinical characteristics of different ADM groups.

\begin{tabular}{|c|c|c|c|c|c|}
\hline & SADM & EADM & BADM & Total & p-Value \\
\hline $\mathbf{n}$ & 25 & 22 & 35 & 82 & \\
\hline Age (yrs) & $49.1 \pm 12.7$ & $51.1 \pm 7.2$ & $50.7 \pm 13.2$ & $50.3 \pm 11.6$ & 0.651 \\
\hline BMI & $22.5 \pm 3.63$ & $22.2 \pm 3.08$ & $22.8 \pm 3.00$ & $22.7 \pm 3.2$ & 0.313 \\
\hline Mastectomy weight (g) & $342 \pm 188$ & $346 \pm 199$ & $354 \pm 158$ & $353 \pm 177$ & 0.924 \\
\hline Implant size $(c c)$ & $348 \pm 131$ & $375 \pm 129$ & $379 \pm 83$ & $373 \pm 111$ & 0.712 \\
\hline Operation duration (min) & $166 \pm 59$ & $150 \pm 40$ & $146 \pm 48$ & $157 \pm 50$ & 0.212 \\
\hline \multicolumn{6}{|l|}{ Diagnosis } \\
\hline DCIS & $6(24 \%)$ & $8(36 \%)$ & $8(23 \%)$ & $22(27 \%)$ & \\
\hline Invasive breast cancer & $15(60 \%)$ & $9(41 \%)$ & $17(48 \%)$ & $41(50 \%)$ & \\
\hline Prophylactic & $4(16 \%)$ & $5(23 \%)$ & $10(29 \%)$ & $19(23 \%)$ & \\
\hline Prior BCT & $9(36 \%)$ & $5(23 \%)$ & $8(23 \%)$ & $22(27 \%)$ & 0.463 \\
\hline Follow-Up & $1246 \pm 722$ & $727 \pm 588$ & $282 \pm 243$ & $646 \pm 404$ & 0.002 \\
\hline
\end{tabular}


Table 3. Major and minor complications of different ADM used for direct-to-implant breast reconstruction.

\begin{tabular}{lccccc}
\hline & $\begin{array}{c}\text { SADM } \\
(\mathbf{n}=\mathbf{2 5})\end{array}$ & $\begin{array}{c}\text { EADM } \\
(\mathbf{n}=\mathbf{2 2})\end{array}$ & $\begin{array}{c}\text { BADM } \\
(\mathbf{n}=\mathbf{3 5})\end{array}$ & $\begin{array}{c}\text { Total } \\
(\mathbf{n}=\mathbf{8 2})\end{array}$ & p-Value \\
\hline Minor Complications & $2(8 \%)$ & $5(22.6 \%)$ & $0(0 \%)$ & $7(8.5 \%)$ & 0.011 \\
Seroma & $1(4 \%)$ & $2(9.1 \%)$ & $0(0 \%)$ & $3(3.7 \%)$ & 0.204 \\
Haematoma & $1(4 \%)$ & $1(4.5 \%)$ & $0(0 \%)$ & $2(2.4 \%)$ & 0.463 \\
Small Size Skin Necrosis & $0(0 \%)$ & $2(9.1 \%)$ & $0(0 \%)$ & $2(2.4 \%)$ & 0.061 \\
Implant Loss & $8(32 \%)$ & $6(27.3 \%)$ & $7(20 \%)$ & $21(25.6 \%)$ & 0.564 \\
$\quad$-Skin Necrosis & $5(20 \%)$ & $4(18.2 \%)$ & $2(5.7 \%)$ & $11(13.4 \%)$ & 0.206 \\
$\quad$-Infection & $3(12 \%)$ & $0(0 \%)$ & $2(5.7 \%)$ & $5(6.1 \%)$ & 0.317 \\
$\quad$-Seroma & $0(0 \%)$ & $1(4.4 \%)$ & $3(8.6 \%)$ & $4(4.9 \%)$ & 0.314 \\
$\quad$-Haematoma & $0(0 \%)$ & $1(4.5 \%)$ & $0(0 \%)$ & $1(4.8 \%)$ & 0.257 \\
Overall Complications & $10(40 \%)$ & $11(50 \%)$ & $7(20 \%)$ & $28(34.1 \%)$ & 0.051 \\
Capsular Contracture & $2(8 \%)$ & $3(13.5 \%)$ & $1(2.9 \%)$ & $6(7.3 \%)$ & 0.31 \\
\hline
\end{tabular}

The mean time of hospitalization was $8.2 \pm 3$ days (SADM $=8 \pm 3.2$ days, $\mathrm{EADM}=10 \pm 2.8$ days, $\mathrm{BADM}=6 \pm 1.3$ days). Patients of the BADM group had a significantly lower hospitalization time compared to the SADM or EADM group $(\mathrm{p}<0.001)$. There were no significant differences between SADM or EADM patients $(\mathrm{p}=0.148)$.

Of all cases, 6 patients underwent implant exchange or secondary autologous reconstruction due to capsular fibrosis (7.3\%). There were no significant differences between the three groups (see Table 3). The mean time between reconstruction and revision due to capsular fibrosis was $35.8 \pm 14.4$ months. 50\% of patients with development of capsular contracture received postmastectomy radiation therapy $(\mathrm{n}=3)$.

Exemplary postoperative results are given in Figure 2.

\section{Discussion}

Although the biological properties of ADM are different and numerous experimental and histological studies exist, which show different potential recipient reactions towards $A D M$, we did not see significant differences between them, clinically. The main reason for implant loss in our study was skin necrosis. While some authors advocate the use of ADM and propose a better perfusion of the skin flap after mastectomy [16], several authors remark that the ADM needs profound perfusion for integration. This might not be the case in critically perfused mastectomy flaps, which ultimately leads to matrix disintegration and possible complications [17] [18] [19] [20]. Rapid integration of ADM is important to avoid complications such as seroma or infection [21]. A study by Kim et al. showed that the use of ADM in case of necrotic mastectomy flap led to higher explantation rates, although only with borderline statistical significance [21]. 
Our own histologic analysis has shown rapid integration of the Braxon ${ }^{\circledast}$ matrix with neo-vascularization, even though we encountered mastectomy flap necrosis (example given in Figure 3).

However, there is no clear data, if and how ADM influences the perfusion of mastectomy flaps. Surgical techniques, like a more radical approach towards mastectomy, might damage the subdermal plexus leading to elevated rates of skin flap necrosis, hence marginalizing the influence of ADM. A study by Rose et al. shows that there is a trend towards higher complication rates if thick
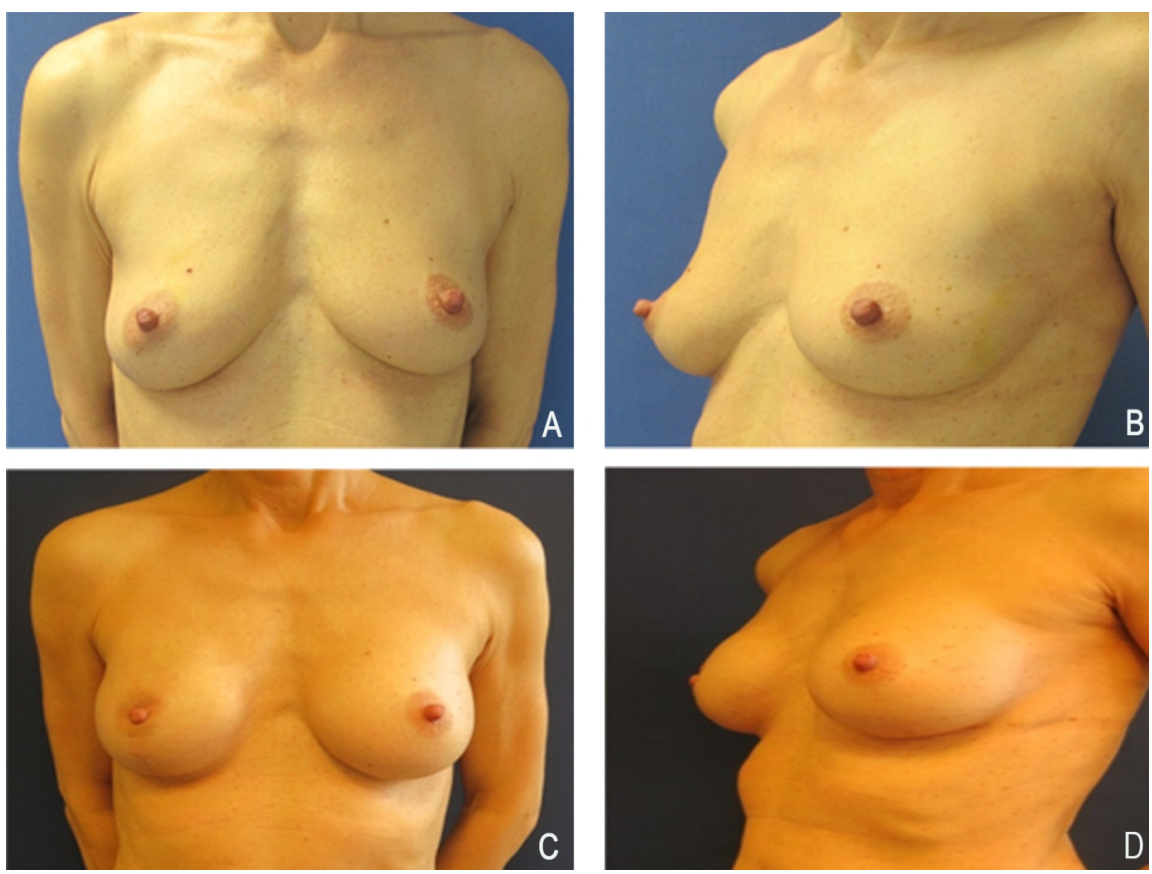

Figure 2. Postoperative result 6 months after right-sided nipple sparing mastectomy and immediate reconstruction with an Allergan ${ }^{\star}$ Style 410 MM $320 \mathrm{cc}$ anatomic implant and Braxon $^{\circledR}$ matrix (A) preoperative anterior view (B) preoperative oblique view (C) postoperative anterior view (D) postoperative oblique view.
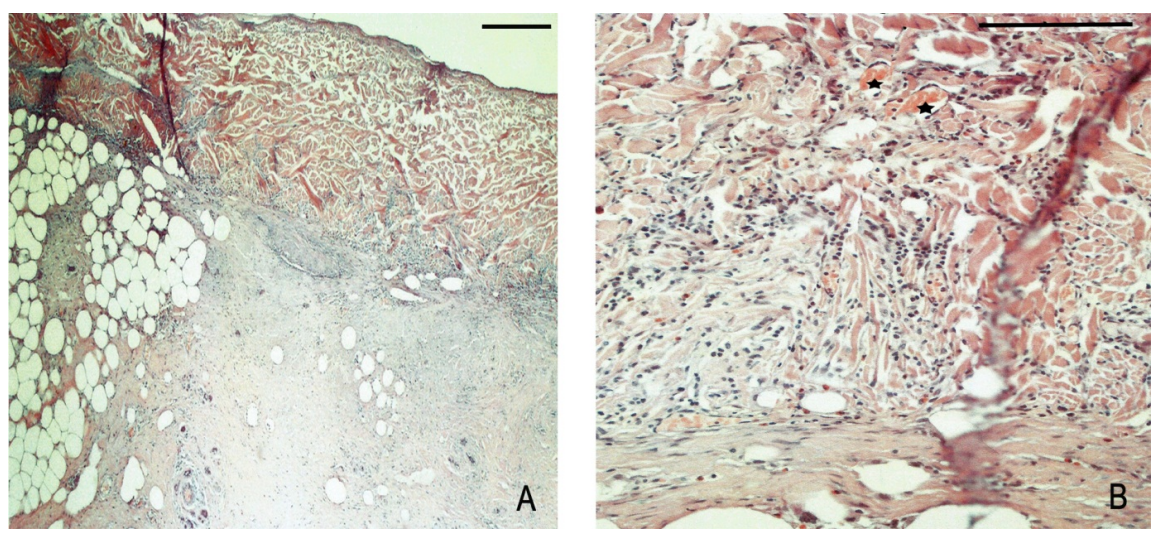

Figure 3. Histological analysis of a piece of Braxon ${ }^{\circledR}$ matrix, which was obtained 3 weeks after implantation due to skin necrosis and subsequent implant and matrix removal. (A) Histiocytic infiltration is evident. The bar indicates $500 \mu \mathrm{m}$. (B) Early neo-vascularization is visible. The vessels are indicated by asterisks. The bar indicates $100 \mu \mathrm{m}$. 
(thickness $>1.2 \mathrm{~mm}$ ) ADM are used [22]. As the thickness of the ADM increases, perfusion and ingrowth of repopulating cells gets more difficult and renders these ADM more prone to failure of integration. This might attribute to the somewhat high complication rate observed in the SADM group, given that the Strattice ${ }^{\varpi}$ ADM was the thickest of the compared ADM (see Table 1).

We have seen significantly fewer minor complications in the BADM group when compared to the EADM group. Furthermore, we have seen a slightly lower rate of implant loss in the BADM group (20\%) compared to SADM (32\%) or EADM (27.3\%), although without reaching statistical significance. Moreover, the time of hospitalization of patients who received Braxon ${ }^{\circledR}$ Matrix was significantly lower when compared to patients who received Strattice ${ }^{\varpi}$ or Epiflex ${ }^{\circledast}$ matrix.

These favorable results might be attributable to the manufacturing process of Braxon $^{\circledast}$ which is free of chemical preservatives. Vittekova et al. showed the different cytotoxic potential of three ADM in vitro. Notably, the cytotoxicity of one ADM remained even after multiple washings [23]. Nevertheless, to our knowledge, there are no studies available at the moment comparing Braxon ${ }^{\circledast}$ and its cytotoxicity with other matrices.

We did not find a significantly lower complication rate for EADM, as has been reported by Paprottka et al. In contrary, Glasberg et al. reported lower complication rates for Strattice ADM compared to AlloDerm. Furthermore, Eichler et al. reported a complication rate of $40.6 \%$ for Epiflex ADM and found it to be significantly higher compared to SurgiMend in a study of 127 patients [24]. These findings can be confirmed to some degree with the current data. It could be shown that the group of patients who received Epiflex had the highest overall complication rate, although without reaching statistical significance. The implant materials' mechanical properties influence the incorporation process between the host tissue and the implant. Given that EADM patients presented with the highest rate of seroma formation, the mechanical properties of this matrix might lead to more encapsulation rather than integration. Roessner et al. found residual donor DNA content on Epiflex matrices which might elicit a pronounced immune response and force encapsulation. The immunogenicity of residual DNA content on biological scaffolds is well-known [25].

The observed overall complication rate is comparable to current literature, although in the upper range. Salzberg et al. report overall complication rates of $3.9 \%$ and implant loss rates of $1.3 \%$. However, the range of reported complication rates is wide. In a study comparing outcomes of three different ADMs (human, porcine and bovine), Paprottka et al. reported a re-operation rate of $23 \%$ of 52 cases. Chun et al. reported skin necrosis in 23.9\% of 269 ADM-assisted breast reconstruction cases and seroma in $14.1 \%$ of their cases. In a study of 121 cases, Rawlani et al. report an overall complication rate of $16.5 \%$ [26]. Antony et al. reported an overall complication rate of $23.6 \%$ in their study of 153 cases [27].

In 11 cases (13.4\%) we observed severe skin necrosis that led to implant loss. $27 \%$ of our patients underwent prior breast conservation therapy which might be a possible cause for an increased number of skin necrosis and surgical side 
infections. Nevertheless, the available literature does not support this assumption [28] [29]. Compared to direct-to-implant cases without the use of ADM, the available literature reports overall early complication rates (within 6 months of surgery) of $16 \%$ - $42 \%$, which might increase up to $70 \%$ in the setting of pre- or postmastectomy radiation therapy and skin necrosis was reported in $7 \%-20 \%$ of analyzed cases [30] [31].

Regarding capsular contracture, our study showed a rate of $7.3 \%$ with no statistically significant differences between the three groups. In a study of 124 cases of breast reconstruction where porcine $\mathrm{ADM}$ has been used, $6 \%$ of non-irradiated breasts and $13 \%$ of irradiated breasts developed capsular contracture III/IV [32]. Salzberg et al. reported capsular contracture as low as $0.4 \%$. In a small series with a 4-year follow up on Braxon-assisted reconstruction cases, there was no evidence of capsular contracture [33]. Our study shows the lowest capsular contracture rate in the BADM group. This might be attributable to the total wrapping of the implant compared to the use of Epiflex ${ }^{\oplus}$ and Strattice ${ }^{\oplus}$ as an inferolateral hammock only, which leaves the implant's bottom side as well as the upper pole exposed [34]. However, the BADM group also had the shortest follow-up time.

The total coverage of implants with BRAXON ${ }^{\circledR}$ requires more material compared to the other two groups which makes sound tissue perfusion mandatory. The cost of using ADM is comparable for all three products and is within a 2000 - 2500 US-Dollar range. To our knowledge, there currently is no additional reimbursement for the use of ADM in Germany.

Furthermore, there were no differences in operation duration between the three groups. The Braxon ${ }^{\circledR}$ matrix is pre-shaped, which makes total implantwrapping easy and takes equal time compared to the inferolateral hammock technique. We did not see any cases of bottoming out. The possibility to suture down the ADM material to the chest wall plays a crucial role in shaping the implant pocket and securing the inferior border. The implant's downward force is disseminated on the virtually tear-resistant ADM rather than to depend on single sutures enforcing the inframammary fold.

The longitudinal character of our study might contain a bias as the experience with ADM use has grown over time and led to better results with the last used Braxon $^{\circledR}$ matrix regardless of the underlying biological properties of the matrix itself. However, the surgeon, who performed the included procedures, is very experienced with skin sparing mastectomies and implant-based immediate breast reconstructions without the use of ADM. As the handling and operative techniques required for successful use of $\mathrm{ADM}$ are comprehensible, the influence of poor technique or handling can likely be neglected. A specific patient selection and preoperative decision making might have led to improved results and lower rates of implant loss. Nevertheless, the similar group characteristics (age and BMI) do not support this assumption. While the total wrapping of the implants with Braxon ${ }^{\oplus}$ matrix might explain the lower rates of capsular contracture, which was observed and which might be a bias regarding this endpoint of 
the study, it does not explain the lower rate of minor complications. This effect is probably due to the fact that more matrix material also requires better perfusion and mandates more remodeling and integration of an increased amount of material compared to a strip of matrix as with Epiflex ${ }^{\oplus}$ or Strattice ${ }^{\oplus}$. We have not used intraoperative skin flap monitoring, which might have led to ADM use in cases with critical mastectomy flap perfusion. As mentioned earlier, to our knowledge no studies are available which clearly underline the role of ADM in enhancing or reducing tissue perfusion. This aspect actually underlines the usefulness of intraoperative skin flap monitoring as a matter of controversy. When we encountered severe disruption of flap perfusion intraoperatively, we changed to a delayed procedure or no ADM-use at all. These cases have not been included in our retrospective study. Finally, we acknowledge the concerns regarding the use of Allergan Style 410 implants. Our study included patients from 2010 to 2018. Allergan Style 410 implants have been recalled in 2019 for concerns regarding their potential to induce BIA-ALCL. During the period from 2010 to 2017 there were no studies or guidelines available which recommended against the use of Allergan Style 410 implants. On the contrary, Unger et al. in 2016 and McGuire et al. in 2017 reaffirmed the safety of these implants [35] [36]. Currently, we do not use these implants, and all our patients who have received these products are closely counseled and monitored for any signs of BIA-ALCL.

\section{Conclusion}

Although our study did not show significant advantages of one specific ADM, it showed a positive tendency towards the use of Braxon ${ }^{\oplus}$ Matrix with lower overall complication rates, and a low rate of capsular contracture. However, the different biological features of the compared ADM might only have marginal influence on clinical outcomes in our study. Low rates of capsular contracture or secondary procedures point out an advantage of ADM-assisted breast reconstruction when compared to implant reconstruction alone. There could be a protective role of $\mathrm{ADM}$ with regards to postoperative radiation therapy although further studies are needed to elucidate this promising feature.

\section{Ethical Approval}

The study was approved by the institutional review board of the University of Rostock, Germany (Registration-Number 2020-0037). The study is in full accordance with the Helsinki Declaration in its revised 2013 version.

\section{Informed Consent}

Patients signed informed consent regarding publishing their data and photographs.

\section{Conflicts of Interest}

The authors declare no conflicts of interest regarding the publication of this paper. 


\section{Role of Authorship}

Dr. Claas Spengler is the responsible and corresponding author of the manuscript. He collected the data, did the statistical analysis, wrote the manuscript and is responsible for the submission process. Dr. Roland Mett is the head physician of the clinic where all cases have been performed. He is the responsible surgeon for all reviewed cases. Dr. Frank Masberg proof-read the manuscript and overviewed the references. He also assisted in taking and processing the shown figures. Prof. Dr. Peter Vogt assisted during planning and conducting the retrospective review, he also proof-read the manuscript. Dr. Tobias Mett is the senior author of the paper. He designed the study, oversaw the data collecting process and assisted in revising and proof-reading the manuscript.

\section{References}

[1] Spear, S.L., Pelletiere, C.V. and Lockwood, M. (2006) Immediate Breast Reconstruction with Tissue Expanders and AlloDerm. In: Spear, S.L., Wiley, S.C., Robb, G.L., Hammond, D.C. and Nahabedian, M.Y., Eds., Surgery of the Breast, Lippincott Williams \& Wilkins, Philadelphia, 484-488.

[2] Sbitany, H. and Langstein, H.N. (2011) Acellular Dermal Matrix in Primary Breast Reconstruction. Aesthetic Surgery Journal, 31, 30S-37S.

https://doi.org/10.1177/1090820X11417577

[3] Ibrahim, A.M.S., Koolen, P.G.L., Ganor, O., Markarian, M.K., Tobias, A.M., Lee, B.T., Mureau, M.A.M., et al. (2015) Does Acellular Dermal Matrix Really Improve Aesthetic Outcome in Tissue Expander/Implant-Based Breast Reconstruction? Aesthetic Plastic Surgery, 39, 359-368. https://doi.org/10.1007/s00266-015-0484-X

[4] Forsberg, C.G., Kelly, D.A., Wood, B.C., Mastrangelo, S.L., DeFranzo, A.J., Thompson, J.T., Marks, M.W., et al. (2014) Aesthetic Outcomes of Acellular Dermal Matrix in Tissue Expander/Implant-Based Breast Reconstruction. Annals of Plastic Surgery, 72, S116-S120. https://doi.org/10.1097/SAP.0000000000000098

[5] Myckatyn, T.M., Cavallo, J.A., Sharma, K., Gangopadhyay, N., Dudas, J.R., Roma, A.A., Deeken, C.R., et al. (2015) The Impact of Chemotherapy and Radiation Therapy on the Remodeling of Acellular Dermal Matrices in Staged, Prosthetic Breast Reconstruction. Plastic and Reconstructive Surgery, 135, 43e-57e.

https://doi.org/10.1097/PRS.0000000000000807

[6] Vaughan, H.A., Loveland, B.E. and Sandrin, M.S. (1994) GAL $\alpha(1,3)$ GAL Is the Major Xenoepitope Expressed on Pig Endothelial Cells Recognized by Naturally Occurring Cytotoxic Human Antibodies. Transplantation, 58, 879-882. https://doi.org/10.1097/00007890-199410270-00003

[7] Gao, H.-W., Li, S.-B., Sun, W.Q., Yun, Z.-M., Zhang, X., Song, J.-W., Gong, F., et al. (2015) Quantification of $\alpha$-Gal Antigen Removal in the Porcine Dermal Tissue by $\alpha$-Galactosidase. Tissue Engineering Part C: Methods, 21, 1197-1204. https://doi.org/10.1089/ten.tec.2015.0129

[8] Roessner, E.D., Vitacolonna, M. and Hohenberger, P. (2012) Confocal Laser Scanning Microscopy Evaluation of an Acellular Dermis Tissue Transplant (Epiflex ${ }^{\circledR}$ ). PLOS ONE, 7, e45991. https://doi.org/10.1371/journal.pone.0045991

[9] Moyer, H.R., Hart, A.M., Yeager, J. and Losken, A. (2017) A Histological Comparison of Two Human Acellular Dermal Matrix Products in Prosthetic-Based Breast Reconstruction. Plastic and Reconstructive Surgery Global Open, 5, e1576. 
https://doi.org/10.1097/GOX.0000000000001576

[10] Glasberg, S.B. and Light, D. (2012) AlloDerm and Strattice in Breast Reconstruction. Plastic and Reconstructive Surgery, 129, 1223-1233.

https://doi.org/10.1097/PRS.0b013e31824ec429

[11] Keifer, O.P., Page, E.K., Hart, A., Rudderman, R., Carlson, G.W. and Losken, A. (2016) A Complication Analysis of 2 Acellular Dermal Matrices in Prosthetic-Based Breast Reconstruction. Plastic and Reconstructive Surgery Global Open, 4, e800. https://doi.org/10.1097/GOX.0000000000000790

[12] Paprottka, F.J., Krezdorn, N., Sorg, H., Könneker, S., Bontikous, S., Robertson, I., Hebebrand, D., et al. (2017) Evaluation of Complication Rates after Breast Surgery Using Acellular Dermal Matrix: Median Follow-Up of Three Years. Plastic Surgery International, 2017, Article ID: 1283735. https://doi.org/10.1155/2017/1283735

[13] Salzberg, C.A., Ashikari, A.Y., Koch, R.M. and Chabner-Thompson, E. (2011) An 8-Year Experience of Direct-to-Implant Immediate Breast Reconstruction Using Human Acellular Dermal Matrix (AlloDerm). Plastic and Reconstructive Surgery, 127, 514-524. https://doi.org/10.1097/PRS.0b013e318200a961

[14] Deva, A.K., Adams, W.P. and Vickery, K. (2013) The Role of Bacterial Biofilms in Device-Associated Infection. Plastic and Reconstructive Surgery, 132, 1319-1328. https://doi.org/10.1097/PRS.0b013e3182a3c105

[15] Breuing, K.H. and Colwell, A.S. (2007) Inferolateral AlloDerm Hammock for Implant Coverage in Breast Reconstruction. Annals of Plastic Surgery, 59, 250-255. https://doi.org/10.1097/SAP.0b013e31802f8426

[16] Liao, E.C. and Breuing, K.H. (2007) Breast Mound Salvage Using Vacuum-Assisted Closure Device as Bridge to Reconstruction with Inferolateral AlloDerm Hammock. Annals of Plastic Surgery, 59, 218-224. https://doi.org/10.1097/SAP.0b013e31802c148c

[17] Chun, Y.S., Verma, K., Rosen, H., Lipsitz, S., Morris, D., Kenney, P. and Eriksson, E. (2010) Implant-Based Breast Reconstruction Using Acellular Dermal Matrix and the Risk of Postoperative Complications. Plastic and Reconstructive Surgery, 125, 429-436. https://doi.org/10.1097/PRS.0b013e3181c82d90

[18] Colwell, A.S., Damjanovic, B., Zahedi, B., Medford-Davis, L., Hertl, C. and Austen, W.G. (2011) Retrospective Review of 331 Consecutive Immediate Single-Stage Implant Reconstructions with Acellular Dermal Matrix. Plastic and Reconstructive Surgery, 128, 1170-1178. https://doi.org/10.1097/PRS.0b013e318230c2f6

[19] Nahabedian, M.Y. (2012) Acellular Dermal Matrices in Primary Breast Reconstruction. Plastic and Reconstructive Surgery, 130, 44S-53S.

https://doi.org/10.1097/PRS.0b013e31825f2215

[20] Jordan, S.W., Khavanin, N., Fine, N.A. and Kim, J.Y.S. (2014) An Algorithmic Approach for Selective Acellular Dermal Matrix Use in Immediate Two-Stage Breast Reconstruction. Plastic and Reconstructive Surgery, 134, 178-188.

https://doi.org/10.1097/PRS.0000000000000366

[21] Kim, S.Y. and Bang, S.I. (2017) Impact of Acellular Dermal Matrix (ADM) Use under Mastectomy Flap Necrosis on Perioperative Outcomes of Prosthetic Breast Reconstruction. Aesthetic Plastic Surgery, 41, 275-281.

https://doi.org/10.1007/s00266-017-0794-2

[22] Rose, J.F., Zafar, S.N. and Ellsworth IV, W.A. (2016) Does Acellular Dermal Matrix Thickness Affect Complication Rate in Tissue Expander Based Breast Reconstruction? Plastic Surgery International, 2016, Article ID: 2867097.

https://doi.org/10.1155/2016/2867097 
[23] Vittekova, M., Dragunova, J., Kabat, P., Bozikova, M., Bakos, D. and Koller, J. (2014) Cytotoxicity Testing of Scaffolds Potentially Suitable for the Preparation of Three-Dimensional Skin Substitutes. Cell Tissue Bank, 15, 345-355. https://doi.org/10.1007/s10561-013-9390-0

[24] Eichler, C., Vogt, N., Brunnert, K., Sauerwald, A., Puppe, J. and Warm, M. (2015) A Head-to-Head Comparison between SurgiMend and Epiflex in 127 Breast Reconstructions. Plastic and Reconstructive Surgery Global Open, 3, e439. https://doi.org/10.1097/GOX.0000000000000409

[25] Gilbert, T.W., Freund, J.M. and Badylak, S.F. (2009) Quantification of DNA in Biologic Scaffold Materials. Journal of Surgical Research, 152, 135-139. https://doi.org/10.1016/j.jss.2008.02.013

[26] Rawlani, V., Buck, D.W., Johnson, S.A., Heyer, K.S. and Kim, J.Y.S. (2011) Tissue Expander Breast Reconstruction Using Prehydrated Human Acellular Dermis. Annals of Plastic Surgery, 66, 593-597. https://doi.org/10.1097/SAP.0b013e3181f3ed0a

[27] Antony, A.K., McCarthy, C.M., Cordeiro, P.G., Mehrara, B.J., Pusic, A.L., Teo, E.H., Disa, J.J., et al. (2010) Acellular Human Dermis Implantation in 153 Immediate Two-Stage Tissue Expander Breast Reconstructions: Determining the Incidence and Significant Predictors of Complications. Plastic and Reconstructive Surgery, 125, 1606-1614. https://doi.org/10.1097/PRS.0b013e3181d4fb2a

[28] Lee, C.-H., Cheng, M.-H., Wu, C.-W., Kuo, W.-L., Yu, C.-C. and Huang, J.-J. (2019) Nipple-Sparing Mastectomy and Immediate Breast Reconstruction after Recurrence from Previous Breast Conservation Therapy. Annals of Plastic Surgery, 82, S95-S102. https://doi.org/10.1097/SAP.0000000000001696

[29] Olson, J., Anderson, L.A., Ying, J., Zhang, M.-M. and Agarwal, J.P. (2017) Nipple Sparing Mastectomy in Patients with Prior Breast Scars. Annals of Plastic Surgery, 78, 22-27. https://doi.org/10.1097/SAP.0000000000000818

[30] Radovanovic, Z., Radovanovic, D., Golubovic, A., Ivkovic-Kapicl, T., Bokorov, B. and Mandic, A. (2010) Early Complications after Nipple-Sparing Mastectomy and Immediate Breast Reconstruction with Silicone Prosthesis: Results of 214 Procedures. Scandinavian Journal of Surgery, 99, 115-118. https://doi.org/10.1177/145749691009900302

[31] Lam, T.C., Hsieh, F., Salinas, J. and Boyages, J. (2018) Immediate and Long-Term Complications of Direct-to-Implant Breast Reconstruction after Nipple- or SkinSparing Mastectomy. Plastic and Reconstructive Surgery Global Open, 6, e1977. https://doi.org/10.1097/GOX.0000000000001977

[32] Lardi, A.M., Ho-Asjoe, M., Junge, K. and Farhadi, J. (2017) Capsular Contracture in Implant-Based Breast Reconstruction-The Effect of Porcine Acellular Dermal Matrix. Gland Surgery, 6, 49-56. https://doi.org/10.21037/gs.2017.01.02

[33] Berna, G., Cawthorn, S.J., Papaccio, G. and Balestrieri, N. (2017) Evaluation of a Novel Breast Reconstruction Technique Using the Braxon ${ }^{\circledR}$ Acellular Dermal Matrix: A New Muscle-Sparing Breast Reconstruction. ANZ Journal of Surgery, 87, 493-498. https://doi.org/10.1111/ans.12849

[34] Schmitz, M., Bertram, M., Kneser, U., Keller, A.K. and Horch, R.U. (2013) Experimental Total Wrapping of Breast Implants with Acellular Dermal Matrix: A Preventive Tool against Capsular Contracture in Breast Surgery? Journal of Plastic, Reconstructive \& Aesthetic Surgery, 66, 1382-1389.

https://doi.org/10.1016/j.bjps.2013.05.020

[35] Unger, J.G., Carrears, J.M., Nagarkar, P., Jeong, H.S. and Carpenter, W. (2016) Allergan Style 410 Implants for Breast Reconstruction: A Prospective Study in Efficacy, Safety, and Symmetry. Plastic and Reconstructive Surgery, 138, 548-555. 
https://doi.org/10.1097/PRS.0000000000002429

[36] McGuire, P., Reisman, N.R. and Murphy, D.K. (2017) Risk Factor Analysis for Capsular Contracture, Malposition, and Late Seroma in Subjects Receiving Natrelle 410 Form-Stable Silicone Breast Implants. Plastic and Reconstructive Surgery, 139, 1-9. https://doi.org/10.1097/PRS.0000000000002837

[37] Kulig, K.M., Luo, X., Finkelstein, E.B., Liu, X.-H., Goldman, S.M., Sundback, C.A., Neville, C.M., et al. (2013) Biologic Properties of Surgical Scaffold Materials Derived from Dermal ECM. Biomaterials, 34, 5776-5784.

https://doi.org/10.1016/j.biomaterials.2013.02.055

[38] Monteiro, G.A., Rodriguez, N.L., Delossantos, A.I. and Wagner, C.T. (2013) Short-Term in Vivo Biological and Mechanical Remodeling of Porcine Acellular Dermal Matrices. Journal of Tissue Engineering, 4.

https://doi.org/10.1177/2041731413490182

[39] Mulier, K.E., Nguyen, A.H., Delaney, J.P., et al. (2011) Comparison of Permacol ${ }^{\mathrm{TM}}$ and Strattice ${ }^{\mathrm{Tw}}$ for the Repair of Abdominal Wall Defects. Hernia, 15, 315-319.

https://doi.org/10.1007/s10029-010-0777-6

[40] Pascual, G., Sotomayor, S., Rodríguez, M., Pérez-Köhler, B. and Bellón, J.M. (2012) Repair of Abdominal Wall Defects with Biodegradable Laminar Prostheses: Polymeric or Biological? PLoS ONE, 7, e52628.

https://doi.org/10.1371/journal.pone.0052628

[41] Molina, C., Giglio, R., Gandhi, R.M., Sicari, B.M., Londono, R., Hussey, G.S., Badylak, S.F., et al. (2019) Comparison of the Host Macrophage Response to Synthetic and Biologic Surgical Meshes Used for Ventral Hernia Repair. Journal of Immunology and Regenerative Medicine, 3, 13-25.

https://doi.org/10.1016/j.regen.2018.12.002

[42] Dieterich, M. and Faridi, A. (2013) Biological Matrices and Synthetic Meshes Used in Implant-Based Breast Reconstruction-A Review of Products Available in Germany. Geburths Frauenheilk, 73, 1100-1106.

https://doi.org/10.1055/s-0033-1350930

[43] Igbal, F.M., Bhatnagar, A. and Vidya, R. (2016) Host Integration of an Acellular Dermal Matrix: Braxon Mesh in Breast Reconstruction. Clinical Breast Cancer, 16, 209-211. https://doi.org/10.1016/j.clbc.2016.06.009 